\title{
Processing the Plastic Materials Separated from SMW +
}

\author{
Radu Kuncser ${ }^{1,2}$, Marius Enache ${ }^{1,2}$, Septimiu Valasutean ${ }^{3}$, Malina Prisecaru ${ }^{1}$, Elena Pop ${ }^{1}$ and \\ Maria Paraschiv 1,4,* \\ 1 Faculty of Mechanical Engineering and Mechatronics, University POLITEHNICA of Bucharest, \\ 313 Splaiul Independentei, 060042 Bucharest, Romania; radu.kuncser@comoti.ro (R.K.); \\ marius.enache@comoti.ro (M.E.); malina.prisecaru@upb.ro (M.P.); elena.pop@upb.ro (E.P.) \\ 2 Romanian R\&D Institute for Gas Turbines -COMOTI, 220D Iuliu Maniu St., 061126 Bucharest, Romania \\ 3 S.C. VITALIA-Servicii Pentru Mediu S.A., 6 Poligonului Street, Boldesti Scaeni, 105300 Prahova, Romania; \\ septimiu.valasutean@vitalia-mediu.ro \\ 4 National Institute of R\&D for Biological Sciences, Department of Biomaterials and Bioproducts, \\ 296 Splaiul Independentei, 060042 Bucharest, Romania \\ * Correspondence: maria.paraschiv1504@upb.ro \\ + Presented at the 16th International Symposium "Priorities of Chemistry for a Sustainable Development" \\ PRIOCHEM, Bucharest, Romania, 28-30 October 2020.
}

Published: 16 November 2020

Keywords: solid municipal waste; pyrolysis; ATG

\section{Introduction}

Solid municipal waste (SMW) may represent a valuable material and/or energy resource if the wastes are well separated. Depending on the management measures and chemical characteristics of the separated materials, dedicated processing paths can be considered [1,2]. Considering this topic, through the CleanTech Project, funded under the frame of POC 2014-2020 Structural Funds Programme, clean technologies for plastic material separated from MSW within the Integrated Management Center from Tarpiu, Bistrita Nasaud County, are developed and optimised.

\section{Materials and Methods}

For this paper, plastic materials separated from MSW were pyrolyzed in a laboratory scale pilot system. The technical parameters were established after performing thermogravimetric analyses using SETSYS TG/DTG -DSC apparatus build by SETARAM.

\section{Results}

Based on the identified characteristic thermal ranges of decomposition identified through thermogravimetric analysis, applied pyrolysis processes carried out in laboratory pilot plant led to more than $65 \%(\mathrm{wt})$ liquid products, $18-24 \%(\mathrm{wt})$ solid products, and the rest was gas product. In Figure 1, the pyrolysis reactor with catalysis module and thermocouples systems is presented, while in Figure 2, a typical thermogravimetric analysis diagram (TG and DTG) is shown. 


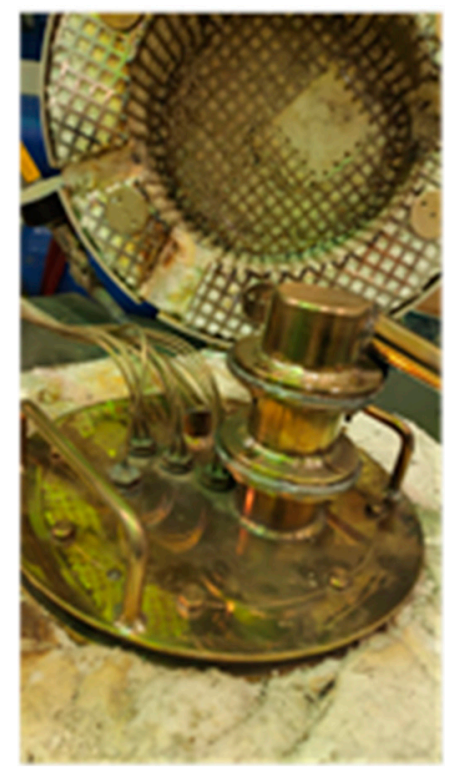

Figure 1. Pyrolysis reactor.

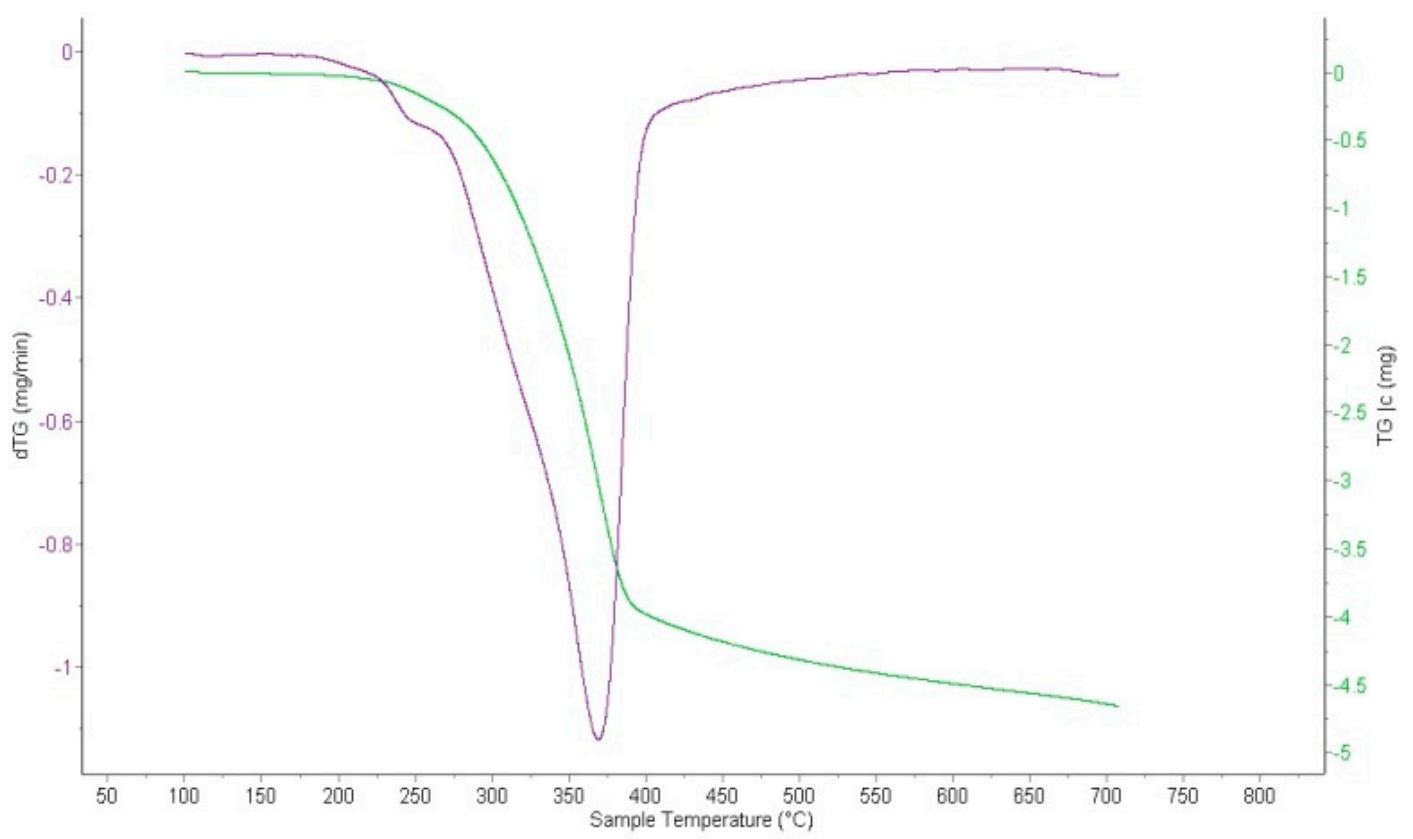

Figure 2. Mass loss (TG) curve and its derivative (DTG).

\section{Conclusions}

By applying controlled thermal profile during the specific range of thermal decomposition of plastic materials, selective components can be recovered and further used for specific application.

Acknowledgments: This work was supported by the Romanian competitiveness operational program (POC 2014-2020) through the knowledge transfer project-CleanTech, POC-P40_308, SMIS: 105958 (http://cleantech.pub.ro/). 


\section{References}

1. Ohidul, A.; Xiuchen, Q. An in-depth review on municipal solid waste management, treatment and disposal in Bangladesh. Sustain. Cities Soc. 2020, 25, 101775.

2. Perrot, J.-F.; Subiantoro, A. Municipal Waste Management Strategy Review and Waste-to-Energy Potentials in New Zealand. Sustainability 2018, 10, 3114, doi:10.3390/su10093114.

Publisher's Note: MDPI stays neutral with regard to jurisdictional claims in published maps and institutional affiliations.

(C) 2020 by the authors. Licensee MDPI, Basel, Switzerland. This article is an open access article distributed under the terms and conditions of the Creative Commons Attribution (CC BY) license (http://creativecommons.org/licenses/by/4.0/). 